\title{
How Successful Is Naturalism?
}

\author{
Michael C. Rea \\ University of Notre Dame
}

\begin{abstract}
The question raised by this volume is "How successful is naturalism?" 1 The question presupposes that we already know what naturalism is and what counts as success. But, as anyone familiar with the literature on naturalism knows, both suppositions are suspect. To answer the question, then, we must first say what we mean in this context by both 'naturalism' and 'success'. I'll start with 'success'. I will then argue that, by the standard of measurement that I shall identify here, naturalism is an utter failure.
\end{abstract}

\section{STANDARDS FOR SUCCESS}

So what would it be for naturalism to be successful? Well, it could be any of a number of things. Naturalism would surely enjoy a kind of success if everyone were to become a naturalist, if becoming a naturalist were regularly and reliably attended by the immediate acquisition of wealth and happiness, if all and only non-naturalists were to spontaneously burst into flames, and so on. But whatever value might attach to these kinds of success, I doubt that they are what most of us are interested in when we inquire after the success of naturalism. Our aims are more modest. When we ask about the success of naturalism, I suspect that what we primarily want to know is whether it is subject to serious objections. If it is not, then it is at least modestly successful. If it is not and its rivals are, all the better.

Two related objections are commonly taken to devastate naturalism: first, that it is self-refuting; second, that it has rationally unacceptable consequences. For reasons that shall become clearer below, I think that both of these objections are non-starters-far from devastating, they aren't even in the right ballpark. So I'll leave them aside. What I want to focus on is a third sort of problem: the malady that a philosophical position suffers from when it rationally commits its adherents to views that are in direct 
tension with whatever attitudes, goals, or values partly characterize the position. For lack of a better label, call this malady dissonance.

Not every philosophical position is characterized in part or whole by values, attitudes, or goals. Lewisian modal realism is a philosophical position, but there is no reason at all to think that anything like goals, values, or attitudes are even partly constitutive of that position. One reason for this is that there is no tradition associated with the position. The set of Lewisian modal realists almost certainly has fewer than ten members; and what unites them is arguably nothing more than adherence to the central thesis of On the Plurality of Worlds. Positions like empiricism, materialism, rationalism, and the like are different, however. Even if there are specific philosophical theses that express these positions, part of what it is to be an empiricist or a materialist or a rationalist is to manifest certain attitudes, goals, or values. As Bas van Fraassen (2002, 58ff.) notes, adherents of these positions "know how to retrench" when developments in science or philosophy come into tension with theses they endorse, and it is the attitudes, goals, and values that serve as guides to the retrenchment.

It is not irrational to embrace a dissonant position, but it is unpleasant. Moreover, the role played by unpleasantness in our decisions about which philosophical positions to adopt is not to be underestimated. Dissonant theories fail along the dimensions of elegance and conservatism: by definition, they demand revision of pre-philosophical attitudes and values, and they break with traditions that we take seriously as guides to the positions we adopt. It is widely acknowledged that elegance and conservatism, among other pragmatic virtues, play an important role in scientific theory choice, and there is no reason to doubt that they play similar roles in philosophical decision making. Indeed, there is every reason to think that their role is all the more vital in decisions about philosophical positions that cannot be formulated as theses-positions like empiricism and materialism as they are understood by van Fraassen (of which more below), and like naturalism as I shall characterize it.

Thus, to accuse a position of being dissonant is to level a serious charge against it. The charge isn't as serious as self-defeat, or incoherence. Nevertheless, a position that is dissonant fails along an important dimension for measuring success. It is in this way, so I shall argue, that naturalism is a failure. 
My argument has the form of a dilemma: If naturalism is a thesis, it is dissonant. If it is not a thesis, it avoids one kind of dissonance but falls prey to another. Either way, then, it is dissonant.

\section{THE NATURE OF NATURALISM}

In my book World Without Design, I argued that naturalism is not a philosophical thesis, but a research program. A research program is a set of methodological dispositions-dispositions to treat certain kinds of arguments or belief-sources as basic sources of evidence. On my view, naturalism is a shared research program - a subset of a maximal set of methodological dispositions ${ }^{1}$ - that treats the methods of science and those methods alone as basic sources of evidence. Among its most important rivals are intuitionism and supernaturalism, which differ only by treating certain additional sources as basic (intuition in the case of intuitionism and religious experience in the case of supernaturalism). A source of evidence is treated as basic just in case it is trusted without reliance on independent evidence in favor of its reliability.

The claim that naturalism is a research program is controversial. But, then again, so is any view about the nature of naturalism: there is really no consensus about what exactly the position involves. Some say that naturalism is a metaphysical view (for example: the view that the universe is a closed causal system). Others say that it is an epistemological view (for example: the view that scientific inquiry is the only avenue to knowledge). Still others say that it is a view about philosophical methodology (for example: the view that philosophers ought to abandon traditional problems about skepticism and ontology and pursue their various projects in a way continuous with the methods of science.) There is broad consensus that, whatever it is, naturalism involves high regard for the methods of science and low-regard for non-scientific modes of theorizing. But a precise and even modestly non-contentious statement of what more is involved in naturalism has yet to appear.

A set of methodological dispositions is maximal just in case it is possible to have all of the dispositions in the set but it is not possible to have all of them and to have other methodological dispositions as well. 
Some say that naturalism comes in different varieties, each expressible by a different philosophical thesis. The typical varieties listed are metaphysical, epistemological, and methodological naturalism. My own view, however, is that there is in fact only one version of naturalism, and many mischaracterizations of it. Given the current state of the literature, to say this is to say that many naturalists have mischaracterized their own naturalism. But I think that there are very good reasons for making this apparently uncharitable claim. In particular, I think that it is the only way for naturalism to avoid a certain kind of dissonance.

Naturalists are united at least in part by dispositions that preclude allegiance to views that cannot be called into question by developments in science. Part of what it is to be a naturalist is to respect the methods of science above all other forms of inquiry and to manifest a disposition to follow science wherever it leads. But if we take this idea seriously, then we are led fairly directly to the conclusion that naturalism couldn't be a substantive philosophical thesis. It is clear that, if naturalism were a thesis, it would be a thesis of metaphysics, epistemology, or philosophical methodology. But the consensus among naturalists is that, in matters of metaphysics, epistemology, and methodology, all of our theories must ultimately be justified by the methods of science, any of our theories might be overthrown by science, and one must follow science wherever it leads. So, on the one hand naturalists are committed to following science wherever it leads; on the other hand, they are committed to thinking that following science wherever it leads might force one to reject any thesis that might plausibly be identified with naturalism. To regard naturalism as a thesis, then, is to suppose that what is really central to naturalism is dogmatic adherence to some view in metaphysics, epistemology, or methodology — such that if the view in question were overthrown by science, naturalists would not retrench, rather they would be refuted. But if that supposition is correct, naturalism is dissonant. For dogmatic adherence to any thesis of metaphysics, epistemology, or methodology is in direct tension with the sort of respect for science and disposition to follow science wherever it leads that lies at the heart of the naturalist tradition. ${ }^{2}$

2 The argument in this paragraph is a slightly modified version of an argument I gave in World Without Design, 51ff. The modifications were inspired by an argument 
To avoid dissonance, then, naturalism must be characterized as something other than a thesis. I suppose there are many other things that it could be: an attitude, a value, a preference, a stance, etc. But it is not clear to me that there is much difference between saying that naturalism is one of these things and saying that it is what I say it is-namely, a research program. At any rate, what does seem clear-and what is most important for present purposes - is that naturalism is best characterized as something other than a thesis; and whatever label one wants to apply to it, what it seems to be most centrally is a plan or disposition to use the methods of science and those methods alone in the development of philosophical theories.

As I have said, this view of naturalism is controversial. But others have held it. ${ }^{3}$ Moreover, as I argued at length in World Without Design, taking naturalism this way fits very nicely with characterizations offered by the most prominent spokesmen for the naturalist tradition in the $20^{\text {th }}$ Century, John Dewey and W. V. Quine. And, furthermore, this view of naturalism faithfully captures what is common to virtually all who call themselves naturalists without immediately rendering naturalism vulnerable to the charge of dissonance.

\section{DISSONANCE FROM ANOTHER SOURCE}

In characterizing naturalism as a research program, I have rendered it immune to a variety of objections. It is not a thesis, so it is not refutable. (And so, for this reason, it cannot be self-refuting as is commonly alleged.) Research programs can have consequences-the consequences of a research program are just those theses to which one is rationally committed by virtue of adopting the research program fully, consistently, and competently. But research programs do not, strictly speaking, imply anything. So one can't refute naturalism by showing that it entails a falsehood. One might hope to show that naturalism has consequences that are rationally unacceptable, but the hope is in vain. For any such maneuver

developed independently by Bas van Fraassen for the conclusion that empiricism is not a philosophical thesis but a "stance". See van Fraassen 2002, Ch. 2, esp. 35 46.

3 To take just two examples, see Sellars 1922, vii, and Forrest 1996, 89. 
is destined to be dialectically ineffective. Again, the consequences of a research program are just those views to which one is rationally committed by virtue of adopting it. So it will be futile to try to convince a naturalist that she should regard the consequences of naturalism-views to which she is in fact rationally committed-as rationally unacceptable. Nevertheless, research programs can still prove dissonant. And this is what we find in the case of naturalism.

Preliminary to showing this, two further features of naturalism must be brought to light. First, unlike empiricism, the close cousin with which naturalism is often mistakenly identified, naturalism is inextricably tied to scientific realism by virtue of treating the methods of science as basic sources of evidence. Precisely because they regard the methods of science as evidential sources, naturalists are committed to thinking that those methods are reliably aimed at truth and that the theories produced by those methods are worthy of belief. This is scientific realism-or, at any rate, it is one variety thereof.

Second, naturalists almost universally take themselves to be committed to an ontology that includes only things that can be investigated by science. This is most evident in the various slogans that have been offered flippantly or in earnest as characterizations of naturalism or of what is sometimes called 'metaphysical' or 'ontological' naturalism. Quine, for example, characterizes naturalism as 'the recognition that it is within science itself, and not in some prior philosophy, that reality is to be identified and described' (1981, 66), the implication being that the correct ontology just is the ontology of science. Likewise, Frederick Schmitt, in the Blackwell Companion to Metaphysics entry on naturalism, characterizes ontological naturalism as the view that only natural objects are real, where 'natural' is understood to refer to whatever is recognized by science. $(1995,343)$ Wilfrid Sellars has famously said that "Science is the measure of all things, of what is that it is, and of what is not that it is not." And Armstrong's characterization of naturalism as the view that reality consists of "nothing but a single, all-embracing spatiotemporal system" $(1980,35)$ seems clearly motivated by commitment to an ontology including nothing beyond objects that can be investigated by science. Of course, these are but a few examples. But as anyone familiar with the literature on naturalism will attest, they are perfectly representative. 
These two commitments lay at the heart of the naturalist tradition. But the trouble is that there is direct tension between these two commitments on the one hand and some of the consequences of naturalism on the other. It is to a defense of this claim that I now turn.

In The Empirical Stance (and elsewhere), Bas van Fraassen distinguishes empiricists from metaphysicians as follows: Metaphysicians give absolute primacy to demands for explanation, and are satisfied with explanations by postulate; empiricists reject demands for explanation at certain points, and are unhappy with explanations by postulate. (2002, 36ff.) In light of van Fraassen's other work, I am inclined to gloss this distinction as follows: The metaphysicians are those for whom explanatory power is an important theoretical virtue, and an epistemic virtue. For metaphysicians, inference to the best explanation (whatever exactly that comes to) is a reliable way of acquiring true beliefs about the world, and if a phenomenon is best explained by the postulation of $x \mathrm{~s}$, then one ought to believe in $x$ s. For empiricists, matters are otherwise: explanatory power is not terribly important, it is not an epistemic virtue, and the fact that postulating $x \mathrm{~s}$ best explains some phenomenon is not much of a reason (if it is any reason at all) for believing in $x$ s. Now, a question: Does naturalism take its stand with the metaphysicians, or with the empiricists?

We might appeal to authorities (like Dewey, Quine, Armstrong, and others) to try to settle this question. But, really, we don't have to since naturalism's commitment to scientific realism settles the question for us. If naturalism were to take its stand with the (van Fraassen-style) empiricists, it would be committed to thinking that the methods of science are not reliably aimed at truth. Why? Because inference to the best explanation plays an important role in scientific theorizing, and appeal to explanatory power plays an important role in scientific theory choice. Thus, to deny that explanatory power is an epistemic virtue is precisely to affirm that scientific theories are sometimes (maybe often) chosen for reasons that are not correlated with likelihood of truth. And in that case, it makes no sense to believe a theory simply because it has been selected by scientific methods. So naturalists, by virtue of their commitment to scientific realism, must take their stand with the metaphysicians: Explanatory power is an epistemic virtue; inference to the best explanation provides reason for belief. 
But now comes trouble. In World Without Design, I argued that naturalists are committed to, among other things, some form of substance dualism. The argument for this conclusion can be summed up as follows:

(i) Naturalists are committed to believing only what can be justified via the methods of science. But,

(ii) though the methods of science provide justification for believing in material objects and for believing that material objects have modal properties, either (a) those methods provide no justification for believing that the modal properties of material objects are intrinsic, or (b) they do so only via pragmatic arguments.

(iii) Constructivism - the thesis that modal properties are minddependent-provides the best explanation for our modal knowledge if (iia) is true; and it also provides the best explanation for the truth-conduciveness of pragmatic arguments. Thus

(iv) if (iia) is true, then naturalists should accept constructivism; and if (iib) is true, naturalists should accept constructivism. But

(v) the modal properties of minds cannot be mind-dependent; thus, (vi) minds cannot be material objects. Therefore,

(vi) naturalists should embrace some form of substance dualism.

The bulk of World Without Design is devoted to defending the premises of this argument; and since the defense is both lengthy and complicated, I won't attempt to summarize it here. Rather, I will simply take the conclusion for granted, and focus my attention on the following two questions that were not taken up in the book: First, why does the argument spell trouble for a naturalist? Second, why —as the opening sentence of this paragraph suggests-does the trouble come from the fact that naturalism takes its stand with the metaphysicians rather than the empiricists?

In regards to the first question, the argument spells trouble for a naturalist because, if it is sound, naturalists are committed to believing in things - souls - that cannot be investigated by the methods of science. But, as I indicated earlier, naturalists are united in part by the view that the 
correct ontology includes nothing that cannot be investigated by the methods of science. Thus we have a point of dissonance. Moreover, the argument depends importantly on the role played by explanatory appeals. The claim that naturalists ought to embrace constructivism is explicitly grounded in the demand for an explanation of our modal knowledge. The claim that constructivism leads to dualism is implicitly grounded in the idea that mind-body dualism provides the best explanation (given constructivism and other constraints imposed by naturalism) for mental phenomena. A van Fraassen-style empiricist might simply beg off of these demands for explanation, but to the extent that naturalists take their stand with the metaphysicians (as characterized above), naturalists cannot dodge the demands. Thus we have our answer to the second question: It is because they take their stand with the metaphysicians that naturalists are forced to accept the untoward ontological consequences that arise out of taking certain demands for explanation seriously.

In sum, then, if the argument just summarized is sound, naturalism falls into dissonance for the following reason: By virtue of its tie to scientific realism, naturalism is committed to taking demands for explanation and inferences to the best explanation with ontological seriousness. But in doing this, it is forced into an ontology that includes things that cannot be investigated by science-an ontology that is different from the sort of ontology to which they take themselves to be committed. Note too that the latter commitment will not be an easy one to give up. It is not as if naturalists thought that they were committed to an ontology of atoms but learned from science that they were committed, say, to an ontology of fields. Rather, the situation is that, whereas they thought they were committed to a purely scientific ontology, in fact they are forced to postulate entities beyond the reach of science to help explain certain phenomena in the world. Of course, one might respond here by saying that the very fact that souls help to explain phenomena in the world shows that they are not beyond the ken of science after all. But in the mouth of a naturalist this reply can only seem fulsome. For, of course, dualists have always taken souls to be explanatory postulates, and naturalists have tended to insist that souls are inadequate explanatory postulates because, among other things, they are beyond the ken of science. 


\section{CONCLUSION}

My argument in this paper has taken the form of a dilemma: Either naturalism is a thesis, or it is not. If it is a thesis, then it falls into dissonance because dogmatic adherence to a thesis is inconsistent with the naturalistic commitment to follow science where it leads. If it is not a thesis, it is still dissonant, but now for another reason. And the other reason is just this: Naturalism is committed to scientific realism, and also to an ontology that includes only things that can be investigated by science. But the commitment to realism forces naturalists to accept arguments that proceed by way of inference to the best explanation; and one such argument shows that naturalists are committed to substance dualism, a thesis that populates our ontology with entities that cannot be investigated by science. Dissonance then, if the demand for explanation is rejected, and dissonance if it is accepted. Thus, to the extent that a theory is successful only if it avoids falling into dissonance, naturalism is a failure.

\section{REFERENCES}

Armstrong, D. M. 1980: "Naturalism, Materialism, and First Philosophy". Reprinted in Moser, P. \& Trout, J. D. (eds.) Contemporary Materialism. New York: Routledge, 35-46.

Forrest, P. 1996: God Without the Supernatural: A Defense of Scientific Theism. Ithaca: Cornell University Press.

Quine, W. V. O. 1981: Theories and Things. Cambridge, MA: Harvard University Press.

Rea, M. 2002: World Without Design: The Ontological Consequences of Naturalism. Oxford: Clarendon Press.

Schmitt, F. 1995: "Naturalism.” In: Kim, J. and Sosa, E. (eds) Companion to Metaphysics. Oxford: Blackwell, 343-345.

Sellars, R. W. 1922: Evolutionary Naturalism. Chicago: Open Court Publishing Company.

Sellars, W. 1963: "Empiricism and the Philosophy of Mind." In: Sellars, W.: Science, Perception, and Reality. London: Routledge and Kegan Paul, 127-196. 
Van Fraassen, B. 2002: The Empirical Stance. New Haven: Yale University Press. 
